\title{
The Relationships between Dyeing Methods and Dyeability in Hair Colouring by Utilising Enzymatic 0xidation of (+)-Catechin
}

\author{
Takanori Matsubara', Chinami Sekí2, Hidekazu Yasunaga ${ }^{2 *}$ \\ ${ }^{1}$ Department of Mechanical Engineering, College of Industrial Technology, Amagasaki, Japan \\ ${ }^{2}$ Department of Fibre Science and Engineering, Kyoto Institute of Technology, Kyoto, Japan \\ Email: *yasunaga@kit.ac.jp
}

Received 23 March 2016; accepted 15 May 2016; published 18 May 2016

Copyright (C) 2016 by authors and Scientific Research Publishing Inc.

This work is licensed under the Creative Commons Attribution International License (CC BY). http://creativecommons.org/licenses/by/4.0/

(c) (i) Open Access

\section{Abstract}

The enzymatic oxidation of $(+)$-catechin (Cat) with copper-containing oxidase, tyrosinase, was applied to hair colouring in the study. The Cat is oxidised to be o-benzoquinone form, the catechinone, which works as the hair dyestuff. Four kinds of hair colouring techniques using Cat were examined and each of their dyeability was compared in order to improve it. The first dyeing method is dyeing hair by the redissolved catechinone, which is preliminarily obtained by the oxidation of Cat (Redissolution Dyeing Method). The second one is dyeing hair in the dye solution just after the dye being formed by the enzymatic reaction (Sequential Dyeing Method). The third one is dyeing hair in solution containing Cat and the dyeing process is accompanied by the oxidation of Cat (Simultaneous Oxidation Dyeing Method). The fourth one is two-step dyeing that the hair immersed in Cat solution at the first step and then it is oxidised enzymatically to colour at the second step (Post-0xidation Dyeing Method). The hair is dyed pale yellow by Redissolution Method, deeper yellowish brown by Sequential and Simultaneous Oxidation Dyeing Method and slightly reddish brown by Post-Oxidation Method with Cat. The order of their dyeability is the Simultaneous Oxidation $\approx$ Post-Oxidation $>$ Sequential $>$ Redissolution Dyeing Method at $30^{\circ} \mathrm{C}$. The dyeability of Redissolution Method increases with an increase in dyeing temperature $(T)$ between $20^{\circ} \mathrm{C}$ $60^{\circ} \mathrm{C}$. In Simultaneous Oxidation Method, the $T$ increment also provides higher dyeability, and the colour of dyed hair becomes duller over $50^{\circ} \mathrm{C}$. The Post-Oxidation Method shows higher dyeability at the lower oxidation temperature $\left(20^{\circ} \mathrm{C}-40^{\circ} \mathrm{C}\right)$.

\section{Keywords}

Catechinone, (+)-Catechin, Bio-Catechol, Hair Dyeing, Enzymatic Oxidation, Tyrosinase

\footnotetext{
${ }^{*}$ Corresponding author.

How to cite this paper: Matsubara, T., Seki, C. and Yasunaga, H. (2016) The Relationships between Dyeing Methods and Dyeability in Hair Colouring by Utilising Enzymatic Oxidation of (+)-Catechin. American Journal of Plant Sciences, 7, 10581066. http://dx.doi.org/10.4236/ajps.2016.77101
} 


\section{Introduction}

The oxidation hair dyeing occasionally gives skin irritation and damages to human hair. The oxidation hair dye products contain some materials working as strong allergens and causing sensitisation symptoms during the dyeing process [1]-[4]. Under such the situation, the last author's research group has been studying novel hair dyeing techniques by using bio-based materials obtained from plants in order to invent safer ones. The $(+)$-catechin $\left((+)-(2 R, 3 S)-5,7,3^{\prime}, 4^{\prime}\right.$-tetrahydroxyflavan-3-ol; Cat Figure 1(a)) is one of the flavonoids extracted from tea plants, gambir (Uncaria gambir), areca (Areca catechu) and so on. The Cat shows reductive action and its catechol group forms complexes with metal ions [5] [6].

It was found that the oxidation product of Cat, which was named catechinone, works as hair dyestuff and the dyestuff does not cause erythema or oedema on skin of rabbits [7]. The main compound of catechinone is 4-(3, 4-dihydro-3 $\alpha, 5,7$-trihydroxy-2H-1-benzopyran-2 $\alpha$-yl)-1,2-benzoquinone (Figure 1(b)) and the dyestuff contains a small amount of chromatic side products [7]. The colour of powder and solution of catechinone are red, and the absorption peak and the strength change with solution $\mathrm{pH}$ and concentration of added salts.

The catechinone dyes hair orange, reddish orange or deep yellowish brown depending on dyeing conditions such as the oxidation method, dye concentration, temperature, $\mathrm{pH}$ and additives [7] [8]. The colour fastness of the hair dyed by catechinone to washing and light (daylight and ultraviolet light) is high enough as same as that of oxidation hair dyes [7] [8]. However, the dyeability of catechinone is not high enough for practical use, because the hair dyeing by using it is mild way and the dye colourant molecules do not vigorously penetrate into hair. Therefore, improving its dyeability without using harmful agents is important and requisite for developing the technique.

The catechinone is obtained by the enzymatic [7] [9] or chemical [10] [11] treatment of Cat, and the oxidation reactions are occurred at the catechol (o-dihydroxybenzene) group of Cat to give a corresponding $o$-quinone. The enzymatic technique shows generally the advantage in the reactivity and selectivity. In the enzymatic way, catechinone is produced from Cat aqueous solution with copper-containing enzyme such as tyrosinase and Lascorbate oxidase [7]. The enzymatic reaction between $(+)$-catechin and tyrosinase requires a large amount of oxygen and consumes rapidly oxygen dissolved in a reaction solution in a few minutes [9]. Continuous introduction of oxygen gas into the reaction solution is needed for the efficient production of catechinone by the enzymatic reaction. The optimum conditions for the production of catechinone are as follows: the higher concentration of dissolved oxygen ( $\geq 1 \mathrm{mM}$ in water), $30^{\circ} \mathrm{C}$ of reaction temperature, $8.4-9.0$ of the solution $\mathrm{pH}$ [9].

The improvement of the dyeability of the hair colouring by catechinone is indispensable as mentioned above. In the research, the relationships of the Cat oxidation and dyeing conditions as dyeing methods to the dyeability of hair in the hair colouring by catechinone were studied. The four kinds of dyeing methods are as follows:

1) Redissolution Dyeing Method: dyeing hair in the dye solution containing redissolved catechinone, which is preliminarily obtained by the enzymatic oxidation of Cat.

2) Sequential Dyeing Method: dyeing hair in the dye solution just after the catechinone being formed by the enzymatic reaction in it.

3) Simultaneous Oxidation Dyeing Method: dyeing hair in solution containing Cat and the dyeing process is accompanied by the enzymatic oxidation of Cat.

4) Post-Oxidation Dyeing Method: hair is immersed into Cat solution at the first step and then the hair is treated in another solution containing enzyme at the second step.<smiles>Oc1cc(O)c2c(c1)O[C@H](c1ccc(O)c(O)c1)[C@H](O)C2</smiles>

(a)<smiles>O=C1C=CC(C2Oc3cc(O)cc(O)c3CC2O)=CC1=O</smiles>

(b)

Figure 1. Chemical structure of (+)-catechin ((a) Cat) and catechinone (b). 
The enzyme used in the study was tyrosinase obtained from mushroom. The effect of temperature in the oxidation and dyeing process on the dyeability of hair was also studied.

\section{Experimental}

\subsection{Materials}

(+)-Catechin (Cat, $M_{\mathrm{w}}=290.27$, Sigma) was used as the dyestuff precursors without further purification. Tyrosinase $\left(M_{\mathrm{w}}=1.28 \times 10^{5}\right.$ [sedimentation velocity diffusion], $1.33 \times 10^{5}$ [light-scattering measurements], $1.20 \times$ $10^{5}$ [electrophoresis], Sigma) was used as received. Disodium hydrogen phosphate $\left(\mathrm{Na}_{2} \mathrm{HPO}_{4}, F_{\mathrm{w}}=141.96\right.$, Nacalai Tesque) and sodium dihydrogen phosphate $\left(\mathrm{NaH}_{2} \mathrm{PO}_{4}, F_{\mathrm{w}}=119.98\right.$, Nacalai Tesque) as pH regulators were used without further purification. Water was used as the solvent after distillation.

The human hair samples (Mathai Japan, obtained from Asians and decolourised white, length: $c a .11 \mathrm{~cm}$ ) were bundled by a nylon band and kept under a low humidity. NLES-227 (Taiko Oil Chemicals) that contains $27 \mathrm{wt} \%$ of sodium dodecyloxypolyoxyethylene sulphate $\left(\mathrm{C}_{12} \mathrm{H}_{25} \mathrm{O} \cdot\left(\mathrm{CH}_{2} \mathrm{CH}_{2} \mathrm{O}\right)_{n} \cdot \mathrm{SO}_{3} \mathrm{Na}\right.$, average $n$ is 2$)$ was used as anionic detergent for washing hair.

\subsection{Dyestuff Preparation by Enzymatic Oxidation}

Catechinone was obtained enzymatically from Cat as reported previously [8] [9]. The dyestuff preparation from $5 \mathrm{mM}$ of Cat was started by the addition of $64 \mathrm{U} \cdot \mathrm{ml}^{-1}$ of tyrosinase in $500 \mathrm{ml}$ of phosphate buffer aqueous solution $\left(0.1 \mathrm{M} \mathrm{NaH} \mathrm{PO}_{4} / \mathrm{Na}_{2} \mathrm{HPO}_{4}, \mathrm{pH}=7.0\right)$, which was saturated with oxygen by introducing $\mathrm{O}_{2}$ gas $(\geq 99.5$ vol $\%$ ) at $30^{\circ} \mathrm{C}$. The obtained solution was concentrated to be powdered.

\subsection{Hair Dyeing}

Dyeing hair was made by four kinds of procedures as follows:

1) Redissolution Dyeing Method

The white hair tress $(0.8 \mathrm{~g})$ was immersed into $0.29 \mathrm{wt} \%$ of the catechinone phosphate buffer aqueous solution $(\mathrm{pH}=7.0,100 \mathrm{ml})$. The catechinone was obtained as described at $\$ 2.2$. The solution was shaken at $100 \mathrm{rpm}$ of shaking speed for $40 \mathrm{~min}$ at $30^{\circ} \mathrm{C}$.

2) Sequential Dyeing Method

The Cat $(10 \mathrm{mM})$ and tyrosinase $\left(70 \mathrm{U} \cdot \mathrm{ml}^{-1}\right)$ were dissolved into phosphate buffer solution $(\mathrm{pH}=7.0)$ and were allowed to stand at $30^{\circ} \mathrm{C}$ for $40 \mathrm{~min}$ with $\mathrm{O}_{2}$ gas being introduced at $100 \mathrm{ml} \cdot \mathrm{min}^{-1}$ of the rate. The hair sample was immersed into the dye solution with $\mathrm{O}_{2}$ gas being introduced at $30^{\circ} \mathrm{C}$ for $40 \mathrm{~min}$. The dyeing solution was shaken as the same way of 1).

3) Simultaneous Oxidation Dyeing Method

The Cat $(10 \mathrm{mM})$ and tyrosinase $\left(70 \mathrm{U} \cdot \mathrm{ml}^{-1}\right)$ were dissolved into phosphate buffer solution $\left(\mathrm{pH}=7.0, \mathrm{O}_{2}\right.$ had been saturated) and the hair sample was immersed into the solution. $\mathrm{O}_{2}$ gas was introduced into the shaken solution at $30^{\circ} \mathrm{C}$ for $40 \mathrm{~min}$.

4) Post-Oxidation Dyeing Method

The hair sample was immersed into $10 \mathrm{mM}$ of Cat solution $(\mathrm{pH}=7.0)$ at $30^{\circ} \mathrm{C}$ for $40 \mathrm{~min}$ and the sample was then dipped into $70 \mathrm{U} \cdot \mathrm{ml}^{-1}$ of tyrosinase solution $\left(\mathrm{pH}=7.0, \mathrm{O}_{2}\right.$ had been saturated) at $30^{\circ} \mathrm{C}$ for 40 min with $\mathrm{O}_{2}$ gas being introduced. Both of the treatment solutions were shaken.

The hair samples were taken out from the solution immediately after each the treatment, washed with $100 \mathrm{ml}$ of $0.8 \mathrm{wt} \%$ sodium dodecyloxypolyoxyethylene sulphate aqueous solution and rinsed twice with $200 \mathrm{ml}$ of distilled water at $35^{\circ} \mathrm{C}$. The samples were air-dried at room temperature.

\subsection{Measurements}

The colour and $K / S$ spectrum of hair were measured by a Konica Minolta CM-2600d spectrocolourimeteremploying $10^{\circ}$-view angle, CIE standard illuminant $\mathrm{D}_{65}$ and SCI (specular component included) mode. All the reflected light from a sample including the regular reflection is integrated under the SCI mode. The resulting colour was expressed in $L^{*} a^{*} b^{*}$ standard colourimetric system (CIE 1976). The $L^{*}$ is the lightness index, and $a^{*}$ and $b^{*}$ are the chromaticity coordinates. The positive values of $a^{*}$ indicate red colours and the negative values 
of that indicate green ones, and the positive values of $b^{*}$ indicate yellow and the negative values indicate blue. The $C^{*}$ is the chroma calculated by $C^{*}=\left\{\left(a^{*}\right)^{2}+\left(b^{*}\right)^{2}\right\}^{1 / 2}$. The $K / S$ value is defined Kubelka-Munk theory [12] [13] and obtained from $K / S=\left(1-R_{\lambda}\right)^{2} / 2 R_{\lambda}$, where $K$ is the absorption coefficient, $S$ the scattering coefficient and $R_{\lambda}$ the reflectance of the light (wavelength: $\lambda$ ) for measured samples. The used human hair is unevenly coloured. Then, the measurements of hair was conducted three times for each three parts (measured area: $3 \mathrm{~mm} \varphi$ ), and they were averaged. The standard deviation of $R_{\lambda}$ is within $0.1 \%-0.2 \%$ and that of colour difference $\left(\Delta E^{*}=\right.$ $\left.\left\{\left(\Delta L^{*}\right)^{2}+\left(\Delta a^{*}\right)^{2}+\left(\Delta b^{*}\right)^{2}\right\}^{1 / 2}\right)$ is within 0.04 . There is individual specificity for each the hair tresses, whereas the tendencies of the relationships between dyeing conditions and dyeability are almost constant.

\section{Results and Discussion}

\subsection{Relationships between Dyeing Methods and Dyeability}

The photographs of undyed hair sample and dyed one by each of the technique: 1) Redissolution; 2) Sequential; 3) Simultaneous Oxidation or 4) Post-Oxidation Dyeing Method using Cat are shown in Figure 2. The treatments were performed with or without $\mathrm{O}_{2}$ gas introduction for the 2) Sequential and 3) Simultaneous Oxidation Dyeing Method in order to observe the effect of oxygen on the dyeability. The dyed hair is pale yellow obtained by the Redissolution Dyeing Method and deeper yellowish brown by the Sequential and Simultaneous Oxidation Dyeing Method. The Sequential and Simultaneous Dyeing Methods with $\mathrm{O}_{2}$ gas give deeper colour of hair as compared with the methods without $\mathrm{O}_{2}$. The most reddish colour of hair is obtained by the 4) Post-Oxidation Dyeing Method as slightly reddish brown. The results of the colour and $K / S$ measurements for the undyed and dyed hair samples are shown in Figure 3, Figure 4 and Table 1. The hair dyed by Post-Oxidation Method with $\mathrm{O}_{2}$ shows highest $a^{*}$ and lowest $L^{*}$ values and that by Simultaneous Oxidation Method with $\mathrm{O}_{2}$ shows highest $b^{*}$ value. The $K / S$ value at $400 \mathrm{~nm}$ for the hair dyed by Simultaneous Oxidation Methods with $\mathrm{O}_{2}$ is highest and that at $550 \mathrm{~nm}$ by Post-Oxidation Method with $\mathrm{O}_{2}$ is highest.

The undyed hair shows very slightly yellow and exhibits lowest $K / S$ spectrum as shown in Figure 4 . The spectra of the dyed hair exhibit higher $K / S$ values under $600 \mathrm{~nm}$ of $\lambda$, especially under $500 \mathrm{~nm}$ as compared with those of undyed one. The samples (Figure 2(c), Figure 2(d) and Figure 2(f)) exhibiting higher $b^{*}$ show higher $K / S$ values at $500 \mathrm{~nm}$ and under, and the samples (Figure 2(c), Figure 2(d), Figure 2(f) and Figure 2(g)) exhibiting higher $a^{*}$ show higher $K / S$ values $500 \mathrm{~nm}$ and over. In particular, the $K / S$ spectrum for Post-Oxidation Method is highest $500 \mathrm{~nm}$ and over.

The dye formation reaction effectively proceeds by a large supply of $\mathrm{O}_{2}$ gas and this contributes the higher dyeability for the Sequential and Simultaneous Methods with $\mathrm{O}_{2}$ gas. The $\mathrm{O}_{2}$ gas supply is essential for proceeding the enzymatic reaction cycle, thus, the rate of dyestuff formation increases by oxygen introduction. In the case of Simultaneous Oxidation Method without $\mathrm{O}_{2}$ gas introduction, oxygen residue in the solution is consumed immediately and the dye formation reaction proceeds slowly. It results in the lower dyeability. In the case of Sequential Method without $\mathrm{O}_{2}$ gas introduction, its reaction time is twice as long as that of Simultaneous Oxidation Method. Therefore, a little bit more dyestuff is produced to give deeper colour to hair as compared

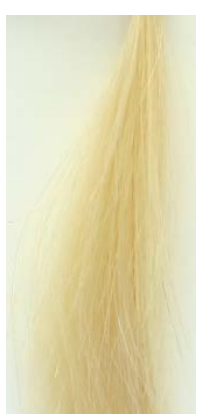

(a)

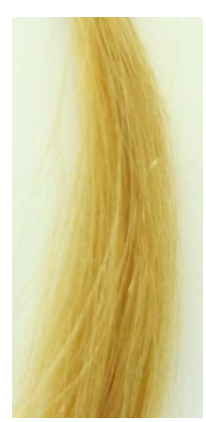

(b)

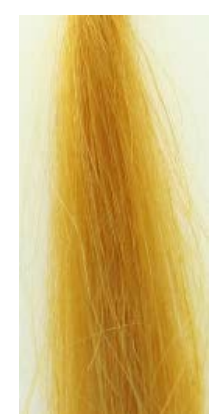

(c)

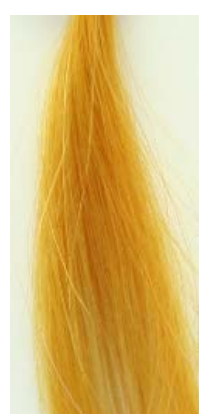

(d)

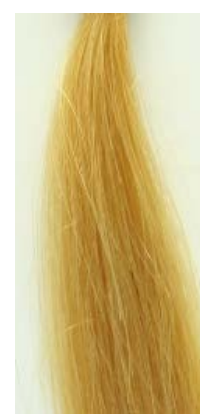

(e)

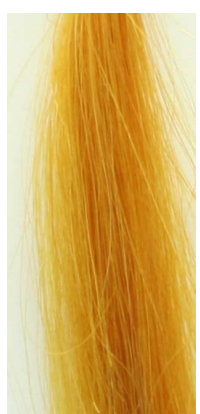

(f)

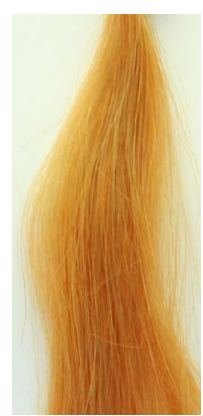

(g)

Figure 2. Photographs of hair samples undyed (a) and dyed by redissolution dyeing method with enzymatically-produced catechinone with $\mathrm{O}_{2}$ gas introduced (b), sequential dyeing method without (c) and with (d) $\mathrm{O}_{2}$ gas, simultaneous oxidation dyeing method without (e) and with (f) $\mathrm{O}_{2}$ gas, and post-oxidation dyeing method $(\mathrm{g})$ with $\mathrm{O}_{2}$ gas by using $(+)$-catechin at $30^{\circ} \mathrm{C}$. 


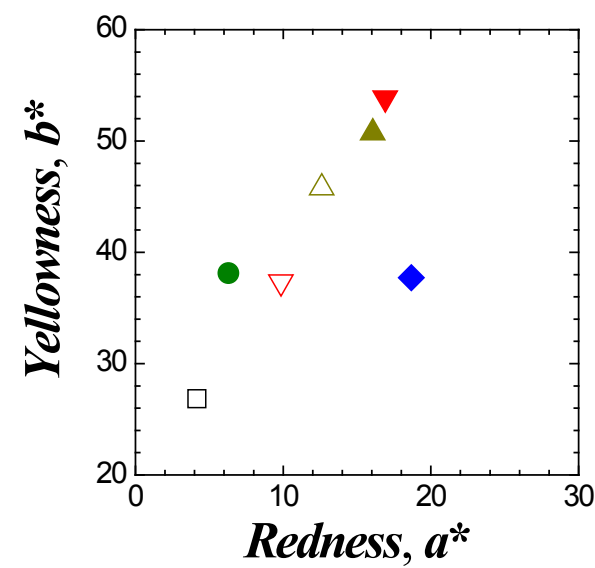

(a)

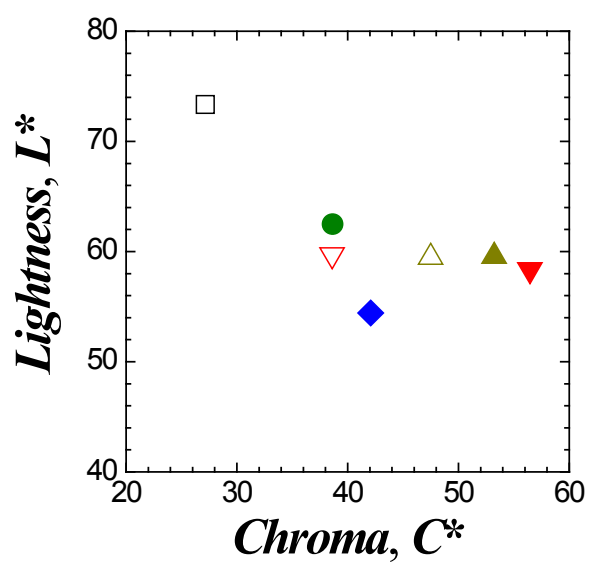

(b)

Figure 3. Colour measurement results of hair samples undyed $(\square)$ and dyed by redissolution dyeing method with catechinone with $\mathrm{O}_{2}$ gas introduced $(\bullet)$, sequential dyeing method without $(\triangle)$ and with $(\triangle) \mathrm{O}_{2}$ gas, simultaneous oxidation dyeing method without $(\nabla)$ and with $(\nabla) \mathrm{O}_{2}$ gas, and post-oxidation dyeing method with $\mathrm{O}_{2}$ gas $(\diamond)$ by using $(+)$-catechin at $30^{\circ} \mathrm{C}$. (a) Chromaticity coordinates relationship $\left(a^{*}-b^{*}\right)$, (b) chroma-lightness index relationship $\left(C^{*}-L^{*}\right)$.

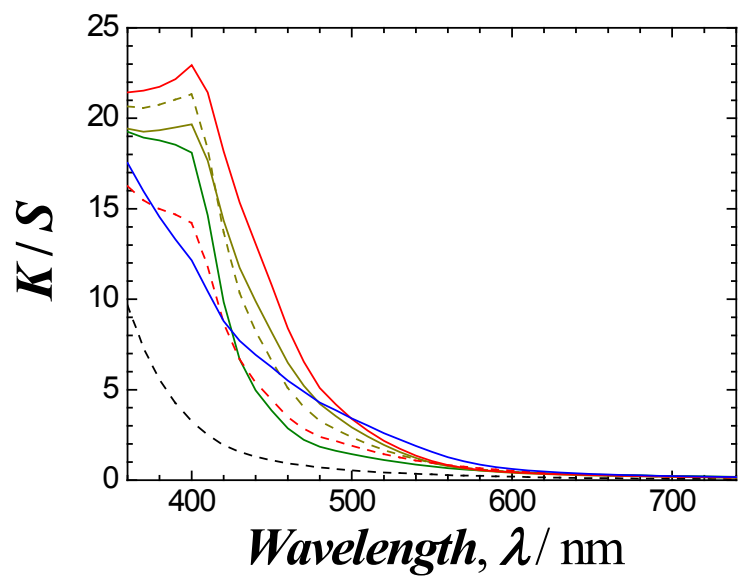

Figure 4. K/S spectra for the hair undyed (---) and dyed by redissolution Dyeing Method with catechinone (-), Sequential dyeing method without (--) and with $(-) \mathrm{O}_{2}$ gas introduced, simultaneous oxidation method without (---) and with $(-) \mathrm{O}_{2}$ gas introduced, and post-oxidation dyeing method $(-)$ by using $(+)$-catechin at $30^{\circ} \mathrm{C}$.

Table 1. The colourimetric values and $K / S$ ones for undyed and dyed hairs.

\begin{tabular}{lcccccccc}
\hline \multirow{2}{*}{ Dyeing method } & \multicolumn{3}{c}{ Colourimetric value } & \multicolumn{3}{c}{$K / S$} \\
\cline { 2 - 8 } & $L^{*}$ & $a^{*}$ & $b^{*}$ & $C^{*}$ & $\Delta E^{* \mathrm{a}}$ & at $400 \mathrm{~nm}$ & at $550 \mathrm{~nm}$ \\
\hline (a) Undyed & 73.4 & 4.16 & 26.8 & 27.2 & - & 3.26 & 0.318 \\
(b) Redissolution with $\mathrm{O}_{2}$ & 62.5 & 6.30 & 38.1 & 38.7 & 15.8 & 18.1 & 0.756 \\
(c) Sequential without $\mathrm{O}_{2}$ & 59.5 & 12.6 & 45.8 & 47.5 & 25.0 & 21.3 & 0.961 \\
(d) Sequential with $\mathrm{O}_{2}$ & 59.6 & 16.1 & 50.7 & 53.2 & 30.1 & 19.7 & 0.966 \\
(e) Simultaneous Oxidation without $\mathrm{O}_{2}$ & 59.7 & 9.85 & 37.7 & 38.6 & 18.1 & 14.2 & 0.953 \\
(f) Simultaneous Oxidation with $\mathrm{O}_{2}$ & 58.4 & 16.9 & 53.9 & 56.5 & 33.4 & 22.9 & 1.06 \\
(g) Post-Oxidation with $\mathrm{O}_{2}$ & 54.4 & 18.7 & 37.7 & 42.1 & 26.2 & 12.1 & 1.56
\end{tabular}

${ }^{a}$ Colour difference between the dyed hair and undyed hair; $\Delta E^{*}=\left\{\left(L^{*}-L^{*}\right)^{2}+\left(a^{*}-a_{0}^{*}\right)^{2}+\left(b^{*}-b^{*}\right)^{2}\right\}^{1 / 2}$, which $L^{*}, a^{*}, b^{*}$ for the dyed hair and $L_{0}^{*}, \quad a_{0}^{*}, \quad b_{0}^{*}$ for the undyed hair. 
with that in the case of Simultaneous Oxidation Method without $\mathrm{O}_{2}$.

The dyeability of Simultaneous Oxidation Method with $\mathrm{O}_{2}$ gas is higher than that of Sequential Method with $\mathrm{O}_{2}$ gas, in spite of the longer oxidation reaction time in Sequential Method. Not only the catechinone is produced, but also dimers and multimers form in the solution during the oxidation of Cat [14] [15]. The reactive $o$-benzoquinone part of catechinone reacts with a raw Cat. The freshly-produced catechinone is consumed to give the dimers and multimers via some reaction routes during the reaction and their amount may increase with time. This may result in the lower dyeability in Sequential Method. The more freshly-produced catechinone in Simultaneous Oxidation Method contributes to the higher dyeability. This explanation is also supported by the fact that Redissolution Method shows lower dyeability and the dyestuff powder used in the method can contain the more dimers and multimers.

Cat molecules are absorbed into and adsorbed onto hair before oxidation process in Post-Oxidation Method, and this is favourable for higher dyeability. On the other hand, Simultaneous Oxidation Method takes the shortest treatment time. This is an important advantage of the method.

\subsection{Effect of Treatment Temperature}

The effect of treatment temperature on the dyeability for each the dyeing method with $\mathrm{O}_{2}$ introduction except for the Sequential Method was investigated in order to improve the dyeability further. In the Post-Oxidation Method, the temperature of the first process and second process was independently controlled. When the first process temperature is controlled from $20^{\circ} \mathrm{C}$ to $60^{\circ} \mathrm{C}$, the second process one was fixed at $30^{\circ} \mathrm{C}$. When the second one is controlled from $20^{\circ} \mathrm{C}$ to $60^{\circ} \mathrm{C}$, the first one was fixed at $30^{\circ} \mathrm{C}$.

In Redissolution Method, the obtained colour of hair becomes deeper with increasing dyeing temperature $(T)$ and its yellowness and $b^{*}$ are the highest at $40^{\circ} \mathrm{C}$ as shown in Figure 5. The $L^{*}$ decreases and $a^{*}$ increases with increasing $T$. Figure 6 (a) shows the $K / S$ spectra for the hair dyed by Redissolution Method at $20^{\circ} \mathrm{C}-60^{\circ} \mathrm{C}$. The strength of the signal at $400 \mathrm{~nm}$ increases with the temperature and reaches maximum at $50^{\circ} \mathrm{C}$. It decreases at $60^{\circ} \mathrm{C}$, whereas the $K / S$ values at $440 \mathrm{~nm}$ and over slightly increase. The $T$ affects on the dye diffusion may contribute largely to the dyeability with catechinone.

Figure 5 indicates that $L^{*}$ for the hair dyed by Simultaneous Oxidation Method with $\mathrm{O}_{2}$ introduction decreases with $T$. Its' $a^{*}$ and $b^{*}$ increase with $T$ up to $40^{\circ} \mathrm{C}$ and decrease over $40^{\circ} \mathrm{C}$. The $K / S$ values at $400 \mathrm{~nm}$ and over $520 \mathrm{~nm}$ increase with $T$ as shown in Figure 6(b). The values at $440-500 \mathrm{~nm}$ decrease with $T$ over $40^{\circ} \mathrm{C}$. On the one hand, the dye formation is inhibited over $40^{\circ} \mathrm{C}$ because tyrosinase is deactivated by heating [9]. On the other hand, the chemical oxidation of Cat with $\mathrm{O}_{2}$ is promoted in some degree at higher $T$ [8]. The dye diffusion may also be accelerated by heating. These mechanisms may cause the dyeing behaviour in Simultaneous Oxidation Method.

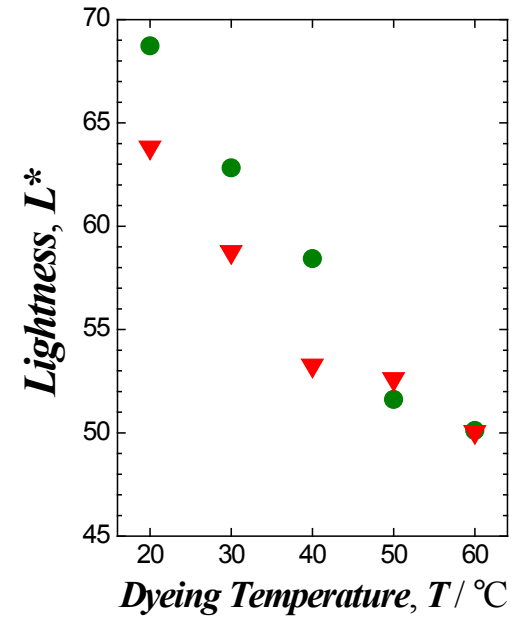

(a)

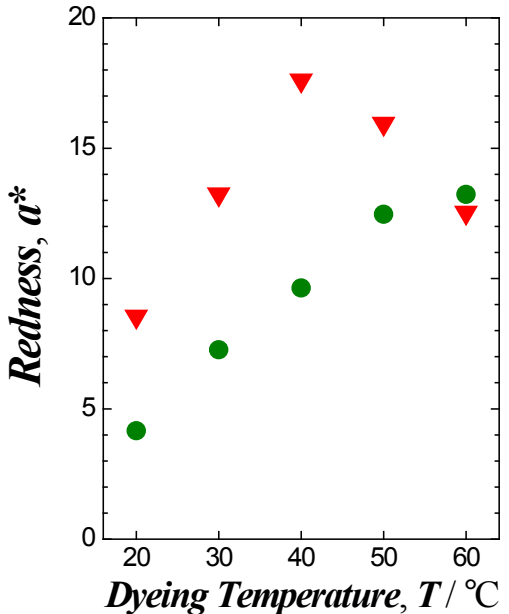

(b)

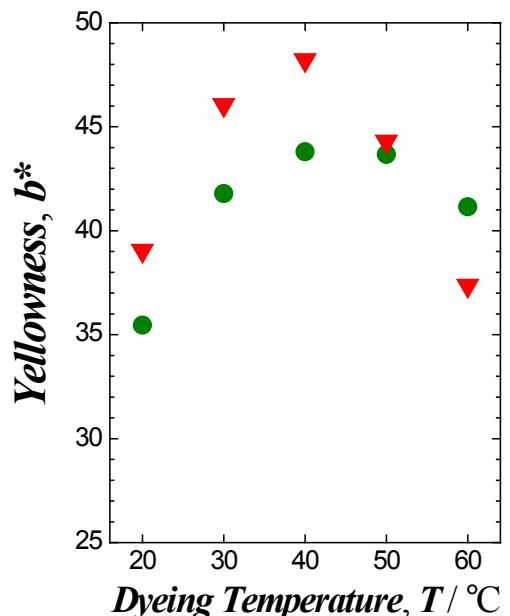

(c)

Figure 5. Dyeing temperature $(T)$ dependence of the $L^{*}(\mathrm{a}), a^{*}(\mathrm{~b})$ and $b^{*}(\mathrm{c})$ for hair dyed by redissolution method with catechinone $(0)$ or simultaneous method with cat $(\nabla)$ in the presence of $\mathrm{O}_{2}$. 


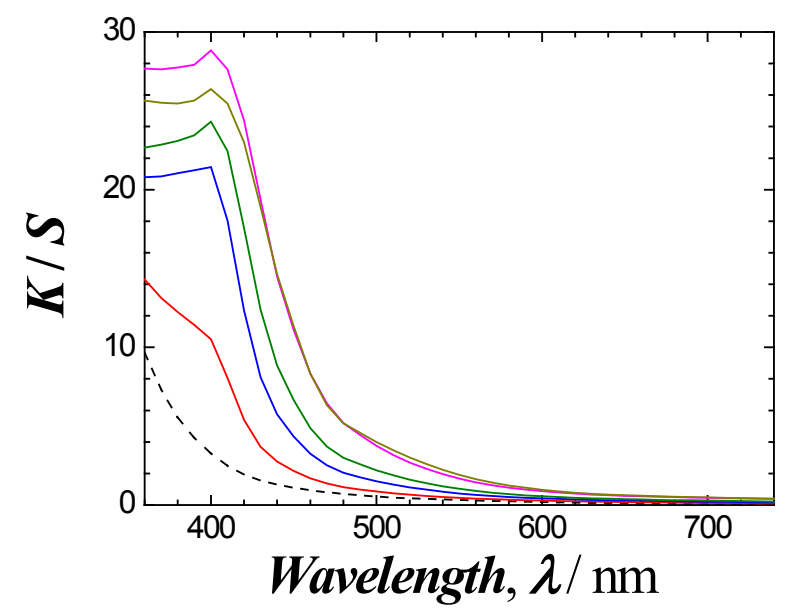

(a)

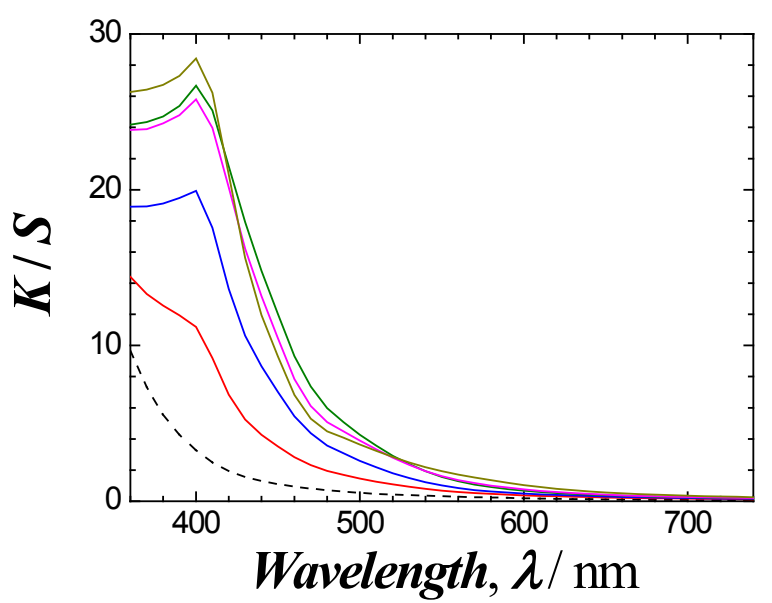

(b)

Figure 6. $K / S$ spectra for the hair undyed (---) and dyed by redissolution Method with catechinone (a) or simultaneous method with Cat (b) at $20(-), 30(-), 40(-), 50(-)$ or $60^{\circ} \mathrm{C}(-)$ in the presence of $\mathrm{O}_{2}$.

In Post-Oxidation Method, the second oxidising process is affected by heating as shown in Figure 7. The $L^{*}$, $a^{*}$ and $b^{*}$ are almost constant at the different temperatures $\left(T_{1}\right)$ of the first process. In contrast, $L^{*}$ increases slightly with increase in the temperature $\left(T_{2}\right)$ of the second process over $40^{\circ} \mathrm{C}$, and $a^{*}$ and $b^{*}$ decrease with $T_{2}$ over $40^{\circ} \mathrm{C}$. Its dyeability is invariable by heating in the first step, whereas the dyeability decreases with an increase in $T_{2}$. The results show that higher temperature in the first process does not promote the absorption and adsorption of Cat to hair. The drawdown of the dyeability by increasing $T_{2}$ over $40^{\circ} \mathrm{C}$ is mainly due to the deactivation of tyrosinase. The $K / S$ spectra for the hair dyed by Post-Oxidation Method are almost same at all the $T_{1}$ and show very slightly change with the increase in $T_{2}$.

The deepest colour of the hair is obtained by Redissolution Method or Simultaneous Oxidation Method at $60^{\circ} \mathrm{C}$. The hair dyed by Simultaneous Oxidation Method at $40^{\circ} \mathrm{C}$ shows the most vivid yellow. The dyeability Post-Oxidation Method at lower temperature $\left(20^{\circ} \mathrm{C}\right.$ and $\left.30^{\circ} \mathrm{C}\right)$ is comparatively high.

\subsection{Proposed Dyeing Mechanism}

The mechanisms of hair dyeing by catechinone are complicated. The interaction between the dyestuffs and dye-sites in hair can be van der Waals force, hydrogen bonding and covalent bonding.

In the Redissolution Method and Sequential Method, it is thought that the dyeing process proceeds via 1) dyestuff approaching surface on hair, 2) penetrating and diffusing into hair, 3) being adsorbed onto hair, 4) being fixed at dye-sites in hair.

The Cat reacts with tyrosinase at the active centre in the enzyme and its molecular weight is $c a$. 130,000, which is too high to penetrate into the hair matrix. Therefore, Cat reacts with tyrosinase and is oxidised in solution, and then dye molecules penetrate into hair and are adsorbed in Simultaneous Oxidation Method. Understandably, Cat penetrates into hair in parallel with the penetration of catechinone. The enzymatic reaction of Cat occurs close to the hair surface in Post-Oxidation Method. The dyeability of Post-Oxidation Method is slightly lower than that of Simultaneous Oxidation Method, because only the Cat molecules, which exist in the vicinity of the hair surface, react with tyrosinase. Other Cat molecules should be supplied from deeper part of the hair. The diffusion rate of Cat molecules in the solution is higher than that in hair.

\section{Conclusion}

The dyeability of the Simultaneous Oxidation and Post-Oxidation Dyeing Method is higher than that of Redissolution and Sequential Dyeing Method for hair by using $(+)$-catechin. The higher temperature $\left(40^{\circ} \mathrm{C}-60^{\circ} \mathrm{C}\right)$ is favourable for the Simultaneous Oxidation and Redissolution Dyeing Method. The Post-Oxidation Dyeing Methodmade at lower temperature $\left(20^{\circ} \mathrm{C}-30^{\circ} \mathrm{C}\right)$ gives higher dyeability. The deactivation of tyrosinase by heating over $50^{\circ} \mathrm{C}$ results in decreasing the dyeability for the Simultaneous Oxidation and Post-Oxidation Dyeing Method. 


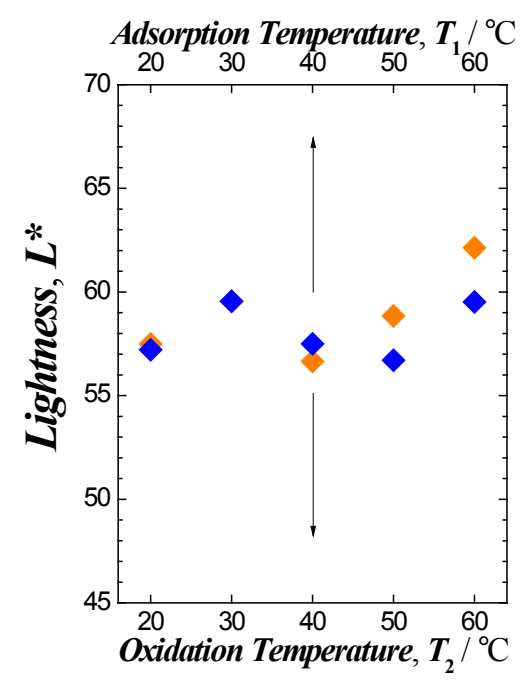

(a)

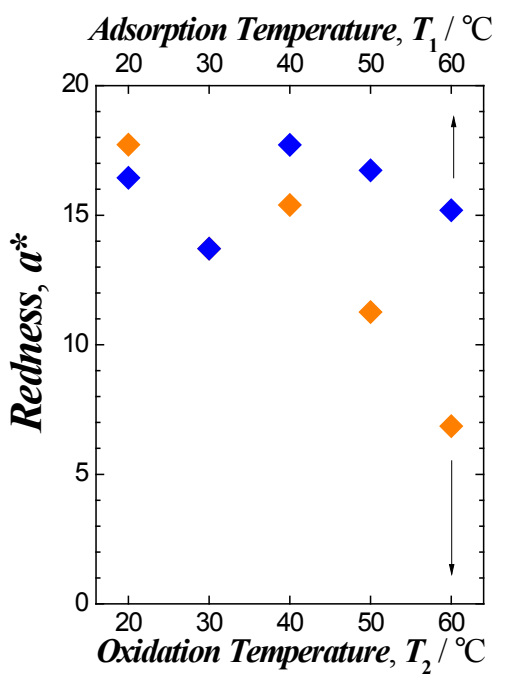

(b)

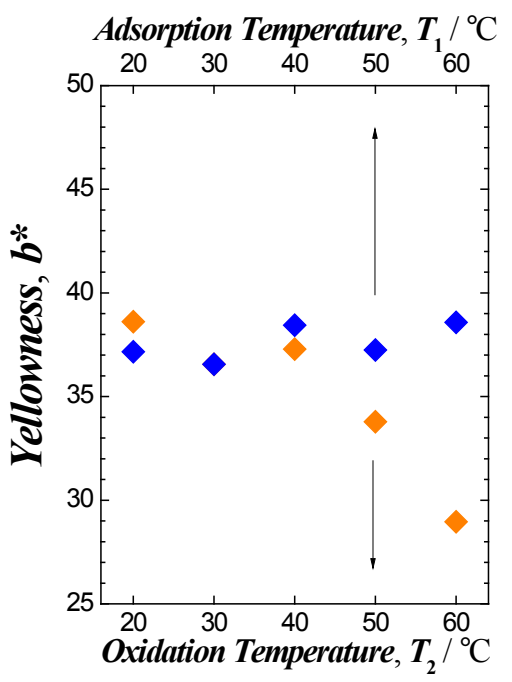

(c)

Figure 7. Adsorption temperature $\left(T_{1}, \diamond\right)$ and oxidation temperature $\left(T_{2}, \diamond\right)$ dependence of the $L^{*}(\mathrm{a}), a^{*}$ (b) and $b^{*}$ (c) for hair dyed by Post-Oxidation Method with Cat in the presence of $\mathrm{O}_{2}$.

\section{Acknowledgements}

This study was financially supported partly by the Japan Society for the Promotion of Science as Grant-in-Aid for Young Scientists (B) (No. 15K16185), the Promotion and Mutual Aid Corporation for Private Schools of Japan as Young Researchers Incentives of the Science Research Promotion Fund and The Cosmetology Research Foundation.

\section{References}

[1] Robbins, C.R. (2012) Chemical and Physical Behavior of Human Hair. 5th edition, Springer-Verlag, Berlin Heidelberg. http://dx.doi.org/10.1007/978-3-642-25611-0

[2] Søsted, H., Agner, T., Andersen, K.E. and Menné, T. (2002) 55 Cases of Allergic Reactions to Hair Dye: A Descriptive, Consumer Complaint-Based Study. Contact Dermatitis, 47, 299-303. http://dx.doi.org/10.1034/j.1600-0536.2002.470508.x

[3] Søsted, H., Rustemeyer, T., Gonçalo, M., Bruze, M., Goossens, A., Giménez-Arnau, A.M., Le Coz, C.J., White, I.R., Diepgen, T.L., Andersen, K.E., Agner, T., Maibach, H., Menné, T. and Johansen, J.D. (2013) Contact Allergy to Common Ingredients in Hair Dyes. Contact Dermatitis, 69, 32-39. http://dx.doi.org/10.1111/cod.12077

[4] Uter, W., Gefeller, O., John, S.M., Schnuch, A. and Geier, J. (2014) Contact Allergy to Ingredients of Hair Cosmetics-A Comparison of Female Hairdressers and Clients Based on IVDK 2007-2012 Data. Contact Dermatitis, 71, 1320. http://dx.doi.org/10.1111/cod.12196

[5] Mira, L., Fernandez, M.T., Santos, M., Rocha, R., Florêncio, M.H. and Jennings, K.R. (2002) Interaction of Flavonoids with Iron and Copper Ions: A Mechanism for Their Antioxidant Activity. Free Radical Research, 36, 1199-1208. http://dx.doi.org/10.1080/1071576021000016463

[6] Torreggiani, A., Juresekova, Z., Sanchez-Cortes, S. and Tamba, M. (2008) Spectroscopic and Pulse Radiolysis Studies of the Antioxidant Properties of (+)-Catechin: Metal Chelation and Oxidizing Radical Scavenging. Journal of Raman Spectroscopy, 39, 265-275. http://dx.doi.org/10.1002/jrs.1849

[7] Yasunaga, H., Takahashi, A., Ito, K., Ueda, M. and Urakawa, H. (2012) Hair Dyeing by Using Catechinone Obtained from (+)-Catechin. Journal of Cosmetics, Dermatological Sciences and Applications, 2, 158-163. http://dx.doi.org/10.4236/jcdsa.2012.23031

[8] Matsubara, T., Taniguchi, S., Morimoto, S., Yano, A., Hara, A., Wataoka, I., Urakawa, H. and Yasunaga, H. (2015) Relationship between Dyeing Condition and Dyeability in Hair Colouring by Using Catechinone Prepared Enzymatically or Chemically from (+)-Catechin. Journal of Cosmetics, Dermatological Sciences and Applications, 5, 94-106. http://dx.doi.org/10.4236/jcdsa.2015.52012

[9] Yano, A., Matsubara, T., Wataoka, I., Urakawa, H. and Yasunaga, H. (2011) Effect of Reaction Condition on Hair Dye Formation Behaviour in Enzymatic Reaction. Proceedings of the 11th Asian Textile Conference, Daegu, 1-4 November 
2011, 1081-1084.

[10] Matsubara, T., Wataoka, I., Urakawa, H. and Yasunaga, H. (2013) Effect of Reaction $\mathrm{pH}$ and $\mathrm{CuSO}_{4} \mathrm{Addition}$ on the Formation of Catechinone Due to Oxidation of (+)-Catechin. International Journal of Cosmetic Science, 35, 362-367. http://dx.doi.org/10.1111/ics.12051

[11] Matsubara, T., Wataoka, I., Urakawa, H. and Yasunaga, H. (2014) High-Efficient Chemical Preparation of Catechinone Hair Dyestuff by Oxidation of (+)-Catechin in Water/Ethanol Mixed Solution. Sen'i Gakkaishi, 70, 19-22. http://dx.doi.org/10.2015/fiber.70.19

[12] Kubelka, P. and Munk, F. (1931) Ein Beitrag zür Optik der Farbanstriche. Zeitschrift für Technische Physik, 12, 593601.

[13] Kubelka, P. (1948) New Contributions to the Optics of Intensely Light-Scattering Materials. Part I. Journal of the Optical Society of America, 38, 448-457. http://dx.doi.org/10.1364/JOSA.38.000448

[14] Guyot, S., Vercauteren, J. and Cheynier, V. (1996) Structural Determination of Colourless and Yellow Dimers Resulting from (+)-Catechin Coupling Catalysed by Grape Polyphenoloxidase. Phytochemistry, 42, 1279-1288. http://dx.doi.org/10.1016/0031-9422(96)00127-6

[15] He, F., Pan, Q.-H., Shi, Y., Zhang, X.-T. and Duan, C.-Q. (2009) Identification of Autoxidation of Flavan-3-Ols in Model Solutions by HPLC-MS/MS. Journal of Mass Spectrometry, 44, 633-640. http://dx.doi.org/10.1002/jms.1536 